\title{
Multi-Stressor Observations and Modeling to Build Understanding of and Resilience to the Coastal Impacts of Climate Change
}

\author{
By Jan Newton, Parker MacCready, Samantha Siedlecki, Dana Manalang, John Mickett, Simone Alin, \\ Ervin “Joe" Schumacker, Jennifer Hagen, Stephanie Moore, Adrienne Sutton, and Roxanne Carini
}

Multiple stressors are affecting the Pacific Northwest (PNW) coastal ocean, including harmful algal blooms (HABs), ocean acidification, marine heatwaves, and hypoxia (low oxygen). While these conditions or events are tied to seasonal cycles such as upwelling periods and multiyear cycles such as El Niño/La Niña, they are becoming increasingly frequent and intense. Additionally, they can have devastating impacts on ecosystem health and human wellbeing, shutting down fisheries, stifling the local economy, threatening food security, and inhibiting cultural practices. For example, increasing ocean acidification has affected shellfish growers' capability to secure reliable product. In 2015, a HAB associated with a marine heatwave shut down crab fisheries from Alaska to Baja for commercial and tribal fishers (McCabe et al., 2016), a closure so impactful that the US Congress included the Fishery Disaster Relief Program for Tribal Fisheries in the Budget Act of 2018. And, an unpredicted hypoxia event in 2015 resulted in the Quinault Indian Nation pulling up crab pots with dead crab. Regional projections indicate increases in warming, ocean acidification, and hypoxia by the end of the century (Siedlecki et al., 2021), so solutions are needed.

The challenge of multi-stressor impacts can be addressed by engaging a variety of partners to collect multi-variable observing and forecast data while increasing both scientific knowledge and application of data and information to real-world needs. The Northwest Association of Networked Ocean Observing Systems (NANOOS, http://www.nanoos. org/) helps sustain long-term observations and forecast models to help communities adapt to and plan for variable and changing ocean conditions, thus increasing resilience. NANOOS is the PNW regional coastal ocean observing system of the US Integrated Ocean Observing System (IOOS). It was recently designated a nexus organization for the UN Decade of Ocean Science for Sustainable Development because of its work to sustain and integrate ocean observations and modeling to produce publicly accessible regional data products that help diverse coastal communities ensure safety, build economic resilience, and increase understanding of the coastal ocean.

NANOOS, in collaboration with regional partners, provides observations of temperature, salinity, oxygen, chlorophyll, carbon dioxide, $\mathrm{pH}$, and HABs from buoy assets off the PNW coast (Figure 1). These observations also support several models such as LiveOcean, which provides 72-hour projections of ocean variables such as temperature, salinity,
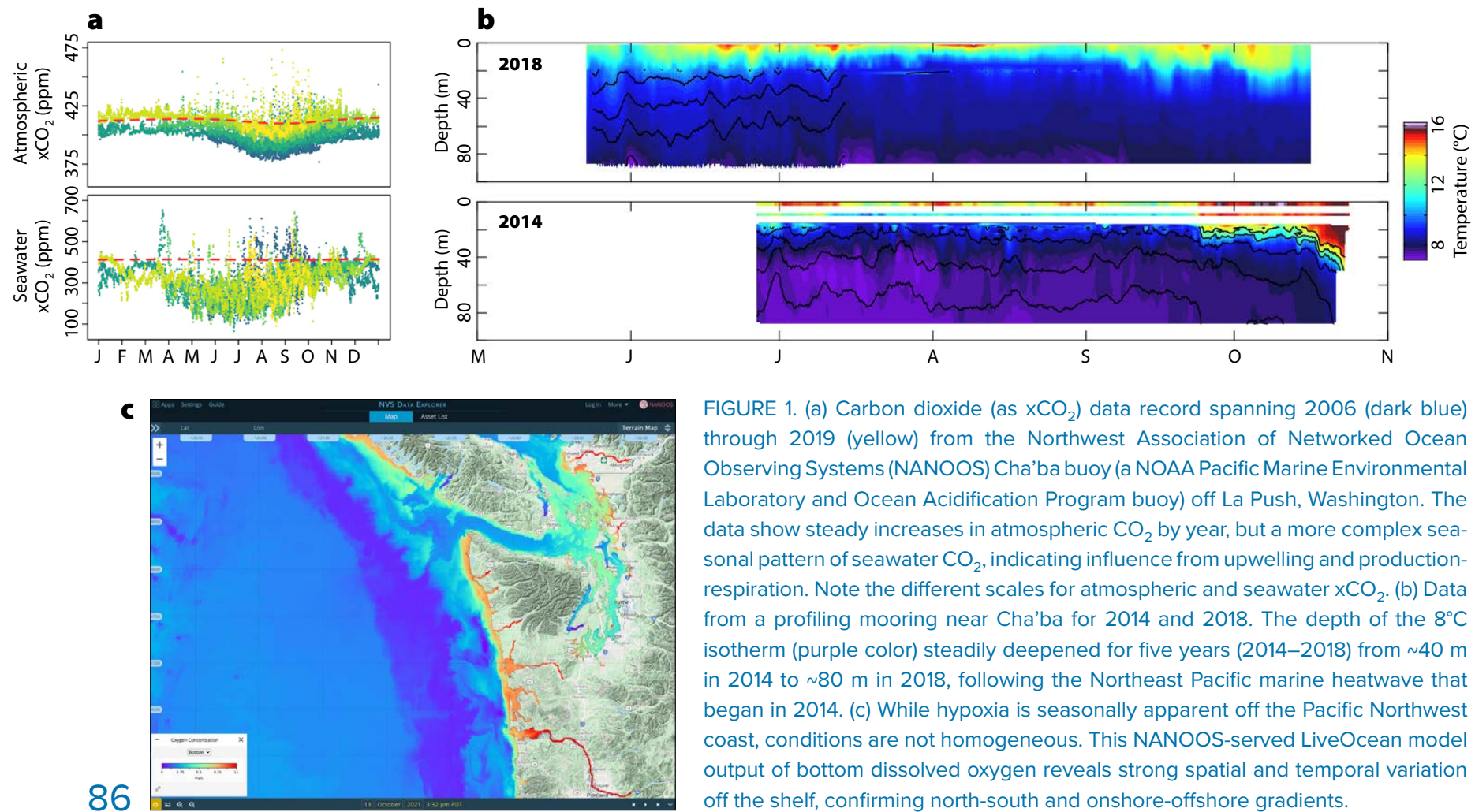

FIGURE 1. (a) Carbon dioxide (as $x \mathrm{CO}_{2}$ ) data record spanning 2006 (dark blue) through 2019 (yellow) from the Northwest Association of Networked Ocean Observing Systems (NANOOS) Cha'ba buoy (a NOAA Pacific Marine Environmental Laboratory and Ocean Acidification Program buoy) off La Push, Washington. The data show steady increases in atmospheric $\mathrm{CO}_{2}$ by year, but a more complex seasonal pattern of seawater $\mathrm{CO}_{2}$, indicating influence from upwelling and productionrespiration. Note the different scales for atmospheric and seawater $x \mathrm{CO}_{2}$. (b) Data from a profiling mooring near Cha'ba for 2014 and 2018. The depth of the $8^{\circ} \mathrm{C}$ isotherm (purple color) steadily deepened for five years (2014-2018) from $40 \mathrm{~m}$ in 2014 to $80 \mathrm{~m}$ in 2018, following the Northeast Pacific marine heatwave that began in 2014. (c) While hypoxia is seasonally apparent off the Pacific Northwest coast, conditions are not homogeneous. This NANOOS-served LiveOcean model output of bottom dissolved oxygen reveals strong spatial and temporal variation off the shelf, confirming north-south and onshore-offshore gradients. 
FIGURE 2. Relying on natural resources, four coastal Pacific Northwest treaty tribes have harvested razor clams on the Washington coast since time immemorial. Photo credit: Quinault Indian Nation

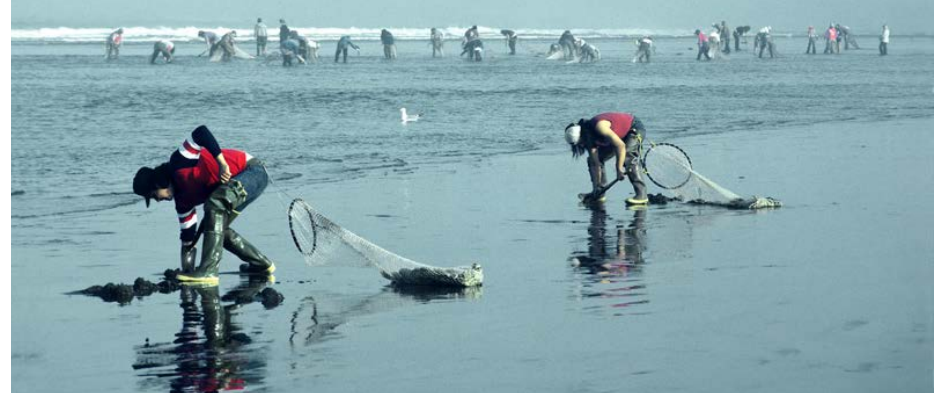

oxygen, and $\mathrm{pH}$. Another model, J-SCOPE, forecasts these conditions six to nine months out. Collectively, data and model outputs are being used by researchers to increase our scientific understanding of coastal dynamics, including HABS, ocean acidification, hypoxia, and marine heatwaves.

This expanding scientific knowledge is a foundation upon which data products are built to aid effective resource management, maritime safety, and other public uses. Data from NANOOS and other federal, academic, tribal, state, and regional programs are integrated and served via tailored data products or applications on the NANOOS Visualization System (NVS), which is freely available to the public and supports a diversity of users. State and tribal resource managers actively use NVS and other NANOOS products to inform decisions on whether to open a beach for clamming or defer crabbing effort. Shellfish growers access information about the present and forecasts of the degree of ocean acidification.

NANOOS assets also provide platforms for testing and developing new technology with partners. With funding from the IOOS Ocean Technology Transition Program and the NOAA National Centers for Coastal Ocean Science, diverse partners deployed a seasonal, real-time $\mathrm{HAB}$-monitoring mooring equipped with an Environmental Sample Processor (ESP), which is an advanced electromechanical fluidics instrument capable of detecting the HAB toxin domoic acid (Moore et al., 2021). ESP observations provide critical information to resource managers via the PNW HAB Bulletin, available on the NANOOS website. Tribal dependency on clam harvest is strong (Figure 2). Further, the contextual observations from adjacent NANOOS moorings have permitted investigation into toxic Pseudo-nitzschia spp. bloom dynamics, including the roles of advection, upwelling, and water property changes. This type of cross-platform analysis can ultimately increase forecast and monitoring effectiveness.

Ocean observing data empower resilience through knowledge. In addition to HABS, hypoxia presents an additional stressor to crab fisheries. The Quileute Tribe utilized funds from the Fishery Disaster Relief Program for Tribal Fisheries to work with the University of Washington Applied Physics Lab to build and deploy two real-time oceanographic moorings that the tribe now owns (Figure 3). The seabed moorings are equipped with oxygen sensors and
FIGURE 3. One of two new hypoxia moorings developed through a partnership among the Quileute Tribe, the University of Washington Applied Physics Laboratory, and NANOOS to aid natural resource managers' fisheries decisions. Photo credit: Jennifer Hagen, Quileute Indian Nation

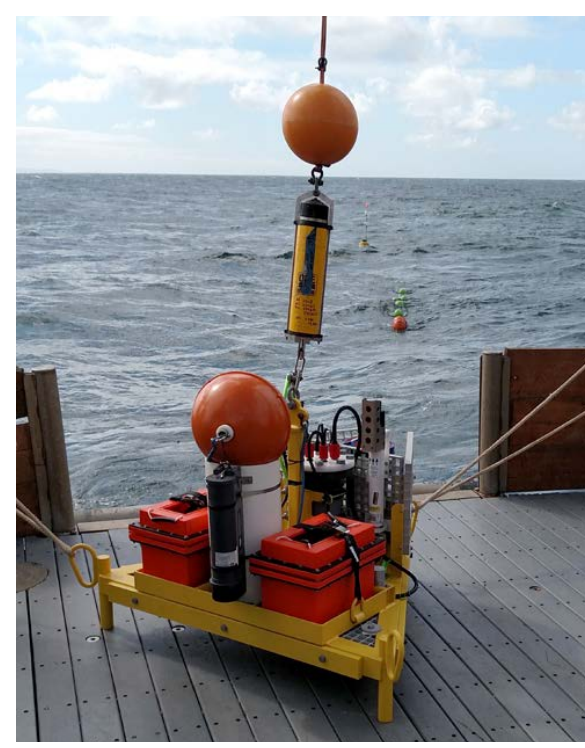

profiling current meters for detecting hypoxic water and measuring its transport, with near-real-time data served by NANOOS. Deployed in June 2021, these moorings provide critical information to inform harvest decisions and will continue to be a valuable resource to the coastal community.

The need for reliable and timely ocean information is strongly felt by coastal communities to ensure their safety, livelihood, and provisioning. Partnerships and integrated multi-use data and models offer diverse user groups the information they need for enhancing resilience to climate change. We conclude that through two human qualitiesthe willingness to partner and the dedication of scientific investigators and technicians (as evidenced by buoy servicing throughout the COVID pandemic)-solutions are being found that increase our collective ability to face these challenges. NANOOS and sister IOOS ocean observing systems were designed to meet society's needs for coastal resilience based on a strong scientific foundation and technology development. Such partnerships, founded on mutual respect and inclusion, must be sustained into the future.

\section{REFERENCES}

McCabe, R.M., B.M. Hickey, R.M. Kudela, K.A. Lefebvre, N.G. Adams, B.D. Bill, F.M.D. Gulland, R.E. Thomson, W.P. Cochlan, and V.L. Trainer. 2016. An unprecedented coastwide toxic algal bloom linked to anomalous ocean conditions. Geophysical Research Letters 43:10,366-10,376, https://doi.org/10.1002/2016GL070023.

Moore, S.K., J.B. Mickett, G.J. Doucette, N.G. Adams, C.M. Mikulski, J.M. Birch, B. Roman, N. Michel-Hart, and J.A. Newton. 2021. An autonomous platform for near real-time surveillance of harmful algae and their toxins in dynamic coastal shelf environments. Journal of Marine Science and Engineering 9:336, https://doi.org/10.3390/jmse9030336.

Siedlecki, S.A., D. Pilcher, E.M. Howard, C. Deutsch, P. MacCready, E.L. Norton, H. Frenzel, J. Newton, R.A. Feely, S.R. Alin, and T. Klinger. 2021. Coastal processes modify projections of some climate-driven stressors in the California Current System. Biogeosciences 18:2,871-2,890, https://doi.org/10.5194/bg-18-2871-2021.

ARTICLE DOI: https://doi.org/10.5670/oceanog.2021.supplement.02-31 


\section{AUTHORS}

Jan Newton (janewton@uw.edu), Northwest Association of Networked Ocean Observing Systems (NANOOS); Applied Physics Laboratory, University of Washington; and School of Oceanography, University of Washington, USA Parker MacCready, School of Oceanography, University of Washington, USA. Samantha Siedlecki, University of Connecticut, USA. Dana Manalang and John Mickett, Applied Physics Laboratory, University of Washington USA. Simone Alin, NOAA Pacific Marine Environmental Laboratory, USA.

Ervin "Joe" Schumacker, Quinault Indian Nation. Jennifer Hagen, Quileute Indian Tribe. Stephanie Moore, Conservation Biology Division, NOAA Northwest Fisheries Science Center, National Marine Fisheries Service, USA. Adrienne Sutton, NOAA Pacific Marine Environmental Laboratory, USA. Roxanne Carini, NANOOS and Applied Physics Laboratory, University of Washington, USA.

\section{ARTICLE CITATION}

Newton, J., P. MacCready, S. Siedlecki, D. Manalang, J. Mickett, S. Alin,

E. Schumacker, J. Hagen, S. Moore, A. Sutton, and R. Carini. 2021. Multi-stressor observations and modeling to build understanding of and resilience to the coastal impacts of climate change. Pp. 86-87 in Frontiers in Ocean Observing: Documenting Ecosystems, Understanding Environmental Changes, Forecasting Hazards. E.S. Kappel, S.K. Juniper, S. Seeyave, E. Smith, and M. Visbeck, eds, A Supplement to Oceanography 34(4), https://doi.org/10.5670/oceanog.2021.supplement.02-31.

\section{COPYRIGHT \& USAGE}

This is an open access article made available under the terms of the Creative Commons Attribution 4.0 International License (https://creativecommons.org/ licenses/by/4.0/), which permits use, sharing, adaptation, distribution, and reproduction in any medium or format as long as users cite the materials appropriately, provide a link to the Creative Commons license, and indicate the changes that were made to the original content. 